\title{
Urinary metabolic profile and stone composition in kidney stone formers with and without heart disease
}

\author{
Matteo Bargagli ${ }^{1}$. Shabbir Moochhala ${ }^{2}$. William G. Robertson ${ }^{2,3}$. Giovanni Gambaro ${ }^{4}$ Gianmarco Lombardi ${ }^{4}$. \\ Robert J. Unwin ${ }^{2} \cdot$ Pietro Manuel Ferraro ${ }^{1,5}$ (I)
}

Received: 9 March 2021 / Accepted: 9 June 2021 / Published online: 21 June 2021

(c) The Author(s) 2021

\begin{abstract}
Objective Kidney stone disease seems to be associated with an increased risk of incident cardiovascular outcomes; the aim of this study is to identify differences in 24-h urine excretory profiles and stone composition among stone formers with and without cardiovascular disease (CVD).

Methods Data from patients attending the Department of Renal Medicine's metabolic stone clinic from 1995 to 2012 were reviewed. The sample was divided according to the presence or absence of CVD (myocardial infarction, angina, coronary revascularization, or surgery for calcified heart valves). Univariable and multivariable regression models, adjusted for age, sex, BMI, hypertension, diabetes, eGFR, plasma bicarbonate and potential renal acid load of foods were used to investigate differences across groups.

Results 1826 patients had available data for 24-h urine analysis. Among these, 108 (5.9\%) had a history of CVD. Those with CVD were older, have higher prevalence of hypertension and diabetes and lower eGFR. Univariable analysis showed that patients with CVD had significantly lower 24-h urinary excretions for citrate ( $2.4 \mathrm{vs} 2.6 \mathrm{mmol} / 24 \mathrm{~h}, \mathrm{p}=0.04)$, magnesium ( $3.9 \mathrm{vs} 4.2 \mathrm{mmol} / 24 \mathrm{~h}, \mathrm{p}=0.03)$ and urinary $\mathrm{pH}(6.1 \mathrm{vs} 6.2, \mathrm{p}=0.02)$. After adjustment for confounders, differences in urinary citrate and magnesium excretions remained significant. No differences in the probability of stone formation or stone compositions were found.

Conclusions Stoneformers with CVD have lower renal alkali excretion, possibly suggesting higheracid retention in stone formers with cardiovascular comorbidities. Randomizedclinical trials including medications and a controlled diet design are neededto confirm the results presented here.
\end{abstract}

\section{Graphic abstract}

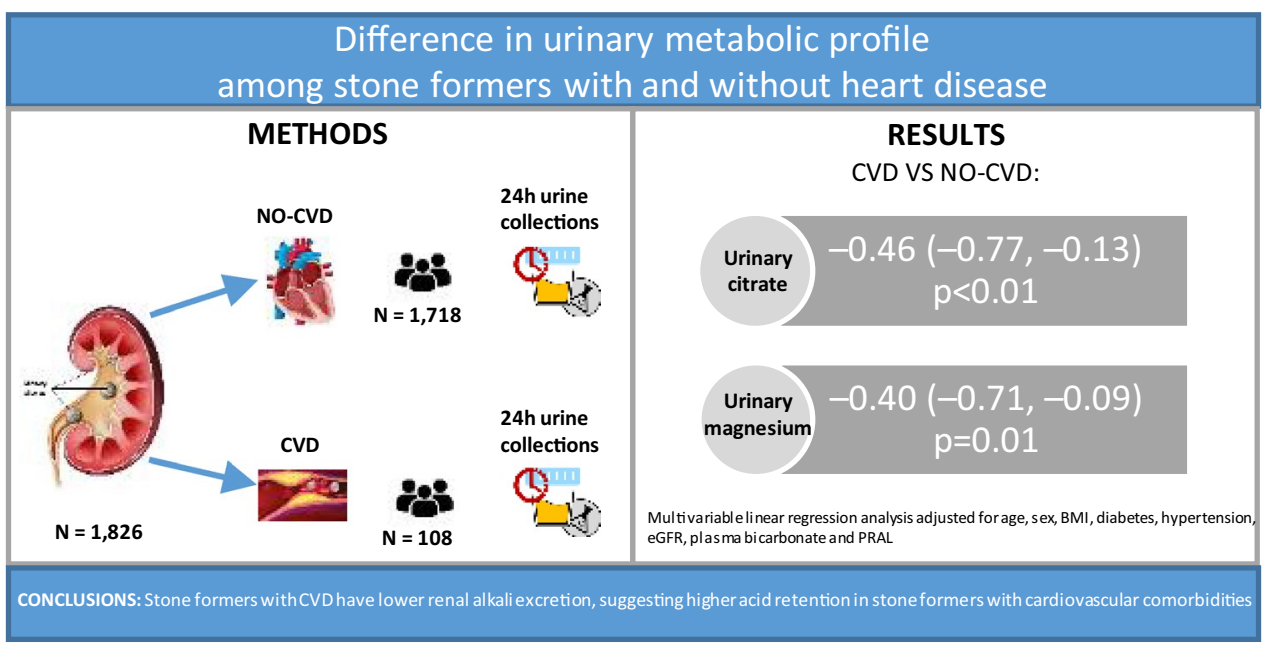

Extended author information available on the last page of the article 
Keywords Kidney stones · Cardiovascular risk · Magnesium · Citrate

\section{Introduction}

Nephrolithiasis is a medical condition with a high prevalence in the general population in Europe and the United States $[1,2]$. Kidney stone disease is a significant clinical and financial burden with an annual expenditure of up to $\$ 10$ billion in the United States alone [3]. The last decades have been characterized by an increase in the incidence of nephrolithiasis associated with a progressive reduction in the male to female ratio, especially in the United States [4]. This may be explained by changes in lifestyle and nutritional habits, leading to more obesity in women, which is a known risk factor for kidney stones. In addition to obesity [5], nephrolithiasis is associated with other comorbidities such as arterial hypertension [6], diabetes mellitus [7] and metabolic syndrome [8]. Nephrolithiasis has also been linked to an increased likelihood of developing chronic kidney disease (CKD) and of cardiovascular events [9], suggesting that kidney stone disease is a systemic disorder, but the reasons for these associations is still unknown.

Recent studies have revealed that kidney stone patients have an increased incidence of specific cardiovascular anomalies such as an augmented pulse-wave velocity, arterial stiffness [10] and vascular calcification [11] when compared with the general population. However, data supporting the link between kidney stones disease and cardiovascular outcomes are from epidemiological studies, and it could be that certain 24-h urine abnormalities are associated with a greater risk of cardiovascular disease (CVD).

Higher urinary citrate excretion prevents lithogenesis, inhibiting the aggregation of calcium-oxalate crystals and neutralizing uric acid supersaturation. Hypocitraturia is a common finding in kidney stone-formers [12] and is also associated with a higher prevalence of abdominal aortic calcification (AAC) [13].

Another mineral involved in kidney stone formation is magnesium. This ion reduces both crystallization and growth of calcium-oxalate stones, so that lower urinary excretion and dietary deficiency are considered risk factors for nephrolithiasis [14]. Furthermore, lower serum magnesium levels have been associated with all-cause mortality, cardiovascular mortality and vascular calcifications in CKD and hemodialysis populations $[15,16]$. Based on this evidence, a recent randomized trial demonstrated the effectiveness of magnesium-oxide supplementation in slowing progression of coronary artery calcification [17].

In light of these observations, the aim of the present study was to investigate differences in 24-h urine excretory profiles and stone composition in stone-formers with and without CVD.

\section{Methods}

\section{Study population and data collection}

We performed a retrospective observational analysis of data from patients attending the UCL Department of Renal Medicine's metabolic stone clinic from 1995 to 2012. Details of the cohort have been reported elsewhere [12]. We included all adult ( $\geq 18$ years old) patients with at least one metabolic assessment of nephrolithiasis (24-h urine analysis). For each patient, demographic, and clinical information (sex, age, body mass index (BMI), comorbidities) were recorded. Cardiovascular disease was defined as the presence of one or more of the following self-reported conditions: myocardial infarction, angina, coronary revascularization, or surgery for calcified heart valves. All included patients performed a fasting blood sample for serum sodium, calcium, magnesium, phosphate, creatinine, plasma bicarbonate, and a 24-h urine collection for measurement of urine volume, urine $\mathrm{pH}$ and 24-h urinary excretion of the following solutes: creatinine, calcium, oxalate, urate, citrate, magnesium, sodium and potassium. Patients also underwent a food frequency questionnaire for dietary determination of daily fluids, sodium, potassium, calcium, magnesium, phosphate, animal protein and fiber intakes. Nutrients consumption from food frequency questionnaires were estimated through a validated software based on McCance and Widdowson's Food Composition Tables [18].

Glomerular filtration rate was estimated (eGFR) using the Chronic Kidney Disease Epidemiology Collaboration equation [19].

Potential renal acid load of foods was calculated as follow: $(0.49 *$ protein intake $)+(0.037 \times$ phosphate intake $)$ $-(0.021 \times$ potassium intake $)-(0.026 \times$ magnesium intake $)$ - $(0.013 \times$ calcium intake $)$ [20].

Hypercalciuria was defined as urine calcium excretion $>6.2 \mathrm{mmol} / 24$-h for women and $7.5 \mathrm{mmol} / 24$-h for men. Hyperuricosuria was considered as urinary uric acid excretion $>4.5 \mathrm{mmol} / 24$ - $\mathrm{h}$ for females and $>4.8 \mathrm{mmol} / 24$ $\mathrm{h}$ for males. Hyperoxaluria was defined as urinary oxalate excretion $>0.5 \mathrm{mmol} / 24$-h for both males and females. Hypocitraturia was considered as urinary citrate excretion $<1.5 \mathrm{mmol} / 24-\mathrm{h}$. Low urine volume was considered as urine volume $<1 \mathrm{~L} / 24-\mathrm{h}$.

Stone compositions were considered to have a single constituent if a proportion greater than $95 \%$ of the stone weight was composed of a single component.

A validated calculation for the risk of stone formation (computation of the probability of stone formation or PSF) 
was obtained for calcium oxalate, calcium phosphate and uric acid in all patients [21].

\section{Statistical analysis}

Continuous variables were reported as means and standard deviations, categorical variables as frequencies and percentages. Differences in 24-h urine composition between stone formers with and without CVD were investigated using Mann-Whitney test, Fisher exact test, univariable and multivariable regression models, adjusted for age, sex, BMI, diabetes, hypertension, eGFR, plasma bicarbonate and PRAL. A p-value $\leq 0.05$ was considered as statistically significant. All analyses were performed with Stata version 16 (StataCorp, Texas, US).

\section{Results}

A total of 1826 patients had available serum parameters and 24-h urine collections and were included in the analysis. Among these, 108 (5.9\%) subjects had history of CVD. Those with CVD were older (59 vs. 46 years, $\mathrm{p}<0.01)$, whereas BMI (27.4 vs. 26.7, p=0.13) and sex was similar (males, 73 vs. $70 \%, p=0.56$ ) between groups. Stone formers affected by CVD have higher prevalence of hypertension and diabetes and lower eGFR (Table 1). Overall, hypercalciuria was the most common urinary abnormalities $(n=658,36 \%)$, followed by hypocitraturia $(n=409,22 \%)$, hyperuricosuria $(n=310,17 \%)$, hyperoxaluria $(n=151,8.3 \%)$ and low urine volume $(n=103$,
Table 1 Baseline characteristics by CVD status

\begin{tabular}{|c|c|c|c|c|}
\hline Variables & All patients $(\mathrm{N}=1826)$ & $\begin{array}{l}\text { No CVD } \\
\text { stone formers } \\
(\mathrm{N}=1718)\end{array}$ & $\begin{array}{l}\text { CVD stone } \\
\text { formers } \\
(\mathrm{N}=108)\end{array}$ & p-value \\
\hline Age, years & $47.2(13.7)$ & $46.5(13.4)$ & $58.8(12.9)$ & $<0.001$ \\
\hline Females & $544(29.8)$ & $515(30.0)$ & $29(26.9)$ & 0.562 \\
\hline Hypertension & $325(17.8)$ & $294(17.1)$ & $31(28.7)$ & 0.012 \\
\hline Diabetes & $118(6.5)$ & $103(6.0)$ & $15(14.9)$ & 0.009 \\
\hline BMI & $26.7(4.9)$ & 26.7 (4.9) & $27.4(4.3)$ & 0.133 \\
\hline $\mathrm{eGFR}, \mathrm{mL} / \mathrm{min} / 1.73 \mathrm{~m}^{2}, \mathrm{CKD}-\mathrm{EPI}$ & $84.1(21.5)$ & $85.1(21.2)$ & $69.7(20.7)$ & $<0.001$ \\
\hline Serum sodium, $\mathrm{mmol} / \mathrm{L}$ & $141.5(2.2)$ & $141.5(2.2)$ & $141.4(2.5)$ & 0.604 \\
\hline Serum potassium, $\mathrm{mmol} / \mathrm{L}$ & $4.30(0.41)$ & $4.31(0.40)$ & $4.27(0.46)$ & 0.383 \\
\hline Plasma bicarbonate, $\mathrm{mmol} / \mathrm{L}$ & $27.6(3.0)$ & $27.6(3.0)$ & $27.6(3.0)$ & 0.902 \\
\hline Serum calcium, mmol/L & $2.42(0.13)$ & $2.42(0.12)$ & $2.43(0.14)$ & 0.391 \\
\hline Serum phosphate, $\mathrm{mmol} / \mathrm{L}$ & $1.07(0.19)$ & $1.07(0.19)$ & $1.04(0.18)$ & 0.092 \\
\hline Serum magnesium, $\mathrm{mmol} / \mathrm{L}$ & $0.83(0.07)$ & $0.83(0.07)$ & $0.83(0.08)$ & 0.186 \\
\hline Urine citrate, $\mathrm{mmol} /$ day & $2.63(1.38)$ & $2.64(1.38)$ & $2.36(1.48)$ & 0.042 \\
\hline Urine potassium, $\mathrm{mmol} /$ day & $70.8(22.0)$ & $70.8(22.1)$ & $71.2(21.3)$ & 0.839 \\
\hline Urine magnesium, mmol/day & $4.21(1.34)$ & $4.22(1.34)$ & $3.93(1.31)$ & 0.026 \\
\hline Urine oxalate, $\mathrm{mmol} / \mathrm{day}$ & $0.35(0.29,0.41)$ & $0.35(0.29,0.41)$ & $0.35(0.30,0.41)$ & 0.638 \\
\hline Urine calcium, mmol/day & $6.39(3.05)$ & $6.42(3.02)$ & $5.84(3.47)$ & 0.053 \\
\hline Urine uric acid, mmol/day & $3.63(1.18)$ & $3.64(1.18)$ & $3.49(1.13)$ & 0.191 \\
\hline Urine creatinine, $\mathrm{mmol} /$ day & $13.3(3.5)$ & $13.3(3.5)$ & $12.9(3.1)$ & 0.178 \\
\hline Urine sodium, mmol/day & $164(60)$ & $164(61)$ & $154(52)$ & 0.078 \\
\hline Urine $\mathrm{pH}$ & $6.20(0.58)$ & $6.20(0.58)$ & $6.07(0.52)$ & 0.020 \\
\hline Urine volume, L/day & $1.93(1.45,2.54)$ & $1.93(1.45,2.55)$ & $1.99(1.45,2.51)$ & 0.918 \\
\hline Low urine volume & $103(5.6)$ & $96(5.6)$ & $7(6.5)$ & 0.861 \\
\hline Hypocitraturia & $409(22.4)$ & $374(21.8)$ & $35(32.4)$ & 0.014 \\
\hline Hypercalciuria & $658(36.0)$ & $626(36.4)$ & $32(29.6)$ & 0.185 \\
\hline Hyperuricosuria & $310(17.0)$ & $295(17.2)$ & 15 (13.9) & 0.454 \\
\hline Hyperoxaluria & $151(8.3)$ & $145(8.4)$ & $6(5.6)$ & 0.381 \\
\hline PSF CaOx & $0.43(0.33)$ & $0.43(0.34)$ & $0.41(0.33)$ & 0.643 \\
\hline PSF CaPi & $0.54(0.30)$ & $0.54(0.29)$ & $0.49(0.33)$ & 0.111 \\
\hline PSF UA & $0.04(0.17)$ & $0.04(0.17)$ & $0.05(0.18)$ & 0.670 \\
\hline
\end{tabular}

Categorical variables are reported as frequencies (\%). Continuous variables are reported as means (SD) or medians (25th, 75th percentile)

$C V D$ cardiovascular disease, $e G F R$ estimated glomerular filtration rate, $P S F$ probability of stone formation 
$5.6 \%)$. Univariable analyses showed that patients with CVD had significantly lower urinary excretions for citrate ( 2.4 vs. $2.6 \mathrm{mmol} / 24-\mathrm{h}, \mathrm{p}=0.04)$ and magnesium ( 3.9 vs. $4.2 \mathrm{mmol} / 24-\mathrm{h}, \mathrm{p}=0.03$ ) associated to lower 24 -h urine $\mathrm{pH}(6.1$ vs. $6.2, \mathrm{p}=0.02)$ and increased prevalence for hypocitraturia (32.4\% vs. $21.8 \%, \mathrm{p}=0.01$ ) (Table 1$)$. Dietary sodium intake was significantly lower in CVD stone formers (170 vs. $176 \mathrm{mmol} / \mathrm{day}, \mathrm{p}=0.04)$ (Table 2). No differences in the remaining dietary component, serum parameters or PSF for calcium oxalate, brushite or uric acid were found between study groups.

A subgroup of 677 patients had available data for stone composition analysis: the proportion of calcium oxalate ( 57 vs. $53 \%, \mathrm{p}=0.54)$, calcium phosphate (19 vs. $28 \%$, $\mathrm{p}=0.09)$, and uric acid ( 16 vs. $12 \%, \mathrm{p}=0.35)$ in analyzed stones was similar for those with and without CVD (Table 3).

After adjustment for age, sex, BMI, diabetes, hypertension, eGFR, plasma bicarbonate and PRAL, urinary uric acid, citrate and magnesium excretions were significantly lower in CVD stone formers, compared with those without heart disease $(\beta:-0.25, \mathrm{p}=0.05 ; \beta:-0.46, \mathrm{p}<0.01 ; \beta$ : $-0.40, p=0.01$, respectively) (Table 4 ). The results were unchanged after removing 177 participants with urine creatinine below or above the sex-specific 5th and 95th percentile.

\section{Discussion}

Kidney stone disease is known to be associated with an increased risk of myocardial infarction and cardiovascular events [22]; moreover, both coronary heart disease and vascular calcification are common findings in patients with kidney stones and CKD [11, 23]. Nephrolithiasis itself is associated with atheroma and vascular calcification: Reiner et al. found an already increased prevalence of carotid artery atherosclerosis in a population of young (aged 18-30 years) patients with a history of kidney stone disease [24]. A subsequent meta-analysis of 11 studies confirmed this finding; nephrolithiasis seems to be associated with an increased cardiovascular risk, especially coronary heart disease and stroke [25].

However, these associations appear to be valid for only some kidney stone phenotypes: we found previously a direct association between calcium phosphate content of stones and the presence of AAC (Odds Ratio (OR) 1.25, $95 \%$ CI 1.00, 1.56, $\mathrm{p}=0.045$ ) [26]. Despite this, the pathophysiological mechanisms underlying the epidemiological association between cardiovascular disease and kidney stone risk are still unresolved.

Table 2 Dietary intake by CVD status

\begin{tabular}{lccc}
\hline Variables & All patients $(\mathrm{N}=1561)$ & $\begin{array}{l}\text { No CVD stone formers } \\
(\mathrm{N}=1455)\end{array}$ & CVD stone formers $(\mathrm{N}=106)$ \\
\hline Fluid intake, L/day & $2.66(2.18,3.27)$ & $2.67(2.18,3.28)$ & $2.53(2.07,3.17)$ \\
Sodium intake, mmol/day & $176.0(146.0,217.0)$ & $176.0(146.0,218.0)$ & $170.0(132.0,204.0)$ \\
Potassium intake, mmol/day & $83.2(20.6)$ & $83.3(20.7)$ & $82.8(19.4)$ \\
Calcium intake, mmol/day & $22.1(18.4,26.9)$ & $22.2(18.4,26.9)$ & $20.8(17.2,27.3)$ \\
Magnesium intake, mmol/day & $15.5(4.0)$ & $15.5(4.0)$ & $14.9(4.2)$ \\
Phosphate intake, mmol/day & $45.3(38.6,52.2)$ & $45.4(38.6,52.3)$ & $43.5(37.9,51.8)$ \\
Oxalate intake, mmol/day & $2.09(1.64,2.65)$ & $2.09(1.64,2.65)$ & $2.08(1.53,2.76)$ \\
Animal protein intake, g/day & $55.9(18.9)$ & $56.0(19.0)$ & $54.9(17.0)$ \\
Fiber intake, g/day & $21.0(17.0,25.4)$ & $20.9(16.9,25.4)$ & $21.0(17.1,25.7)$ \\
PRAL, mEq/day & $-10.3(16.5)$ & $-10.3(16.6)$ & $-10.5(16.5)$ \\
\hline
\end{tabular}

Continuous variables are reported as means (SD) or medians (25th, 75 th percentile)

$C V D$ cardiovascular disease, $P R A L$ potential renal acid load

Table 3 Stone composition by CVD status

\begin{tabular}{lllll}
\hline Variables & All patients $(\mathrm{N}=677)$ & $\begin{array}{l}\text { No CVD stone formers } \\
(\mathrm{N}=631)\end{array}$ & $\begin{array}{l}\text { CVD stone formers } \\
(\mathrm{N}=46)\end{array}$ & p-value \\
\hline CaOx stones & $0.53(0.40)$ & $0.53(0.40)$ & $0.57(0.41)$ & 0.543 \\
CaPi stones & $0.27(0.32)$ & $0.28(0.33)$ & $0.19(0.27)$ & 0.089 \\
UA stones & $0.12(0.31)$ & $0.12(0.31)$ & $0.16(0.36)$ & 0.345 \\
\hline
\end{tabular}

Continuous variables are reported as means (SD)

$\mathrm{CaO} x$ calcium oxalate, $\mathrm{CaPi}$ calcium phosphate, $\mathrm{UA}$ uric acid, $\mathrm{CVD}$ cardiovascular disease 
Table 4 Multivariable regression models for CVD status

\begin{tabular}{lllll}
\hline & $\begin{array}{l}\text { N of obser- } \\
\text { vations }\end{array}$ & $\beta$ coefficient & $95 \%$ confidence interval & p-value \\
\hline Serum sodium, mmol/L & 1201 & 0.05 & $-0.48,0.59$ & 0.845 \\
Serum potassium, mmol/L & 1197 & -0.01 & $-0.11,0.08$ & 0.784 \\
Serum calcium, mmol/L & 1201 & -0.01 & $-0.05,0.02$ & 0.400 \\
Serum phosphate, mmol/L & 1197 & -0.02 & $-0.07,0.02$ & 0.346 \\
Serum magnesium, mmol/L & 1196 & -0.001 & $-0.02,0.02$ & 0.894 \\
Urine citrate, mmol/day & 1201 & -0.45 & $-0.77,-0.13$ & 0.006 \\
Urine potassium, mmol/day & 1201 & -2.79 & $-7.68,2.10$ & 0.264 \\
Urine magnesium, mmol/day & 1201 & -0.40 & $-0.71,-0.09$ & 0.012 \\
Urine oxalate, mmol/day & 1201 & -0.05 & $-0.11,0.02$ & 0.184 \\
Urine calcium, mmol/day & 1201 & -0.54 & $-1.26,0.18$ & 0.140 \\
Urine uric acid, mmol/day & 1201 & -0.25 & $-0.50,-0.003$ & 0.047 \\
Urine sodium, mmol/day & 1201 & -10.37 & $-24.10,3.36$ & 0.139 \\
Urine pH & 1201 & 0.09 & $-0.03,0.20$ & 0.150 \\
Urine volume, L/day & 1201 & -0.03 & $-0.13,0.06$ & 0.504 \\
\hline
\end{tabular}

Multivariable linear regression analysis between CVD status and serum and urinary parameters, adjusted for age, sex, BMI, diabetes, hypertension, eGFR, plasma bicarbonate and PRAL

$C V D$ cardiovascular disease

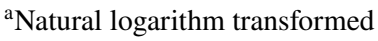

In the present study, $5.9 \%$ of patients were affected by cardiovascular disease. In the univariable analysis, urine $\mathrm{pH}$, urinary citrate and magnesium excretions were significantly lower in CVD stone formers, when compared with patients without cardiovascular risk factors. CVD stone formers appear to be older, have a lower eGFR and a higher prevalence of diabetes and hypertension. However, after adjusting for potential confounders, including age and sex, BMI, diabetes, hypertension, eGFR, plasma bicarbonate and PRAL, differences in urinary excretions of citrate and magnesium remained statistically significant between the study groups.

A common pathway linking CVD and kidney stones is hypocitraturia. A recent retrospective analysis of 97 stone formers showed the association between AAC and lower urinary citrate excretion compared with controls (399 vs. $593 \mathrm{mg} / 24-\mathrm{h}, \mathrm{p}<0.001)$. Furthermore, after adjusting for confounders, AAC was found to be associated with hypocitraturia $(<320 \mathrm{mg} / 24-\mathrm{h}$, OR 4.37, p=0.005) [13]. Low urinary rcitrate excretion is one of the most common 24-h urine abnormalities found in calcium phosphate stone formers [26].

Metabolic syndrome, type 2 diabetes and underlying insulin resistance are well known risk factors for both cardiovascular events and uric acid nephrolithiasis, a kidney stone phenotype characterized by a more acidic urine $\mathrm{pH}$ and hypocitraturia $[8,27,28]$. However, in the present study, after adjusting for diabetes and BMI, urinary citrate excretion remained significantly different across groups, possibly indicating that a different mechanism, other than $\mathrm{pH}$, is involved. In addition, lower urinary citrate excretion was accompanied by similar plasma bicarbonate concentrations, dietary alkali intake and PRAL of foods, between stone formers with and without cardiovascular disease. Since urinary citrate excretion has been found recently to be superior to plasma bicarbonate concentration in detecting latent metabolic acidosis in CKD patients [29, 30], our results may $s$ indicate higher acid retention in stone-formers with cardiovascular comorbidities.

To try to explain our results, we reviewed the role of magnesium in prevention of CVD. Magnesium is critical in both cardiac remodeling, myocardial contraction and relaxation [15], and in the inhibition of calcium-oxalate crystallization [14]. Furthermore, the main regulator of magnesium balance is not bone turnover or gastrointestinal uptake, but its renal handling [31]. However, the effect of reduced urinary magnesium excretion on clinical outcomes seems to be controversial: a higher risk for CVD was observed in those with reduced urinary magnesium excretion in a general population, although plasma magnesium concentrations or dietary intake were not provided[32]. More recently, after adjusting for several potential confounders, a positive association between 24-h urinary magnesium and cardiovascular events was found in patients with CKD and normal serum magnesium levels [33]. This may be related to an impaired ability of the kidney to completely reabsorb the filtered load of magnesium in CKD.

As already described, lower serum magnesium levels are associated with a higher risk for cardiovascular events and magnesium-containing supplements can slow progression of coronary artery calcification in CKD patients [17]. However, 
in our investigation, lower urinary magnesium excretion was observed despite similar dietary magnesium intake and serum magnesium levels between study groups. Of note, a slightly lower urinary uric acid excretion was noted in CVD stone-formers. Diuretics are known to alter the renal excretion of citrate, magnesium and uric acid[34-36] and our findings may, at least in part, be influenced by differences in medical treatment across the groups.

This study has several limitations, including incomplete data on medications, the cross-sectional design, lack of longitudinal information and follow-up, and of exposure validation.

In conclusion, our research is the first to demonstrate that stone-formers affected by heart disease have a multifactorial 24-h urine pattern characterized by lower urinary excretions of both citrate and magnesium. Since citrate and magnesium have been implicated in the pathogenesis of arterial plaque formation, as well as being protective factors in nephrolithiasis, this might indicate a shared underlying pathogenesis. Furthermore, the reduction in renal alkali excretion observed suggests higher acid retention in stone-formers with cardiovascular comorbidities. Since there is a lack of prospective studies, randomized clinical trials that include medications and a controlled diet design are needed to confirm these observations.

Funding Open access funding provided by Università Cattolica del Sacro Cuore within the CRUI-CARE Agreement.

\section{Declarations}

Conflict of interest PMF received consultant fees/grant support from Allena Pharmaceuticals, Alnylam, AstraZeneca, BioHealth Italia, Vifor Fresenius and author royalties from UpToDate; RJU is currently employed by AstraZeneca BioPharmaceuticals R\&D, Early CVRM (Cardiovascular, Renal and Metabolism), Cambridge UK and Gothenburg Sweden; MB and PMF are members of the European Reference Network for Rare Kidney Diseases (ERKNet) - Project ID No 739,532; all the other authors have no disclosures.

Open Access This article is licensed under a Creative Commons Attribution 4.0 International License, which permits use, sharing, adaptation, distribution and reproduction in any medium or format, as long as you give appropriate credit to the original author(s) and the source, provide a link to the Creative Commons licence, and indicate if changes were made. The images or other third party material in this article are included in the article's Creative Commons licence, unless indicated otherwise in a credit line to the material. If material is not included in the article's Creative Commons licence and your intended use is not permitted by statutory regulation or exceeds the permitted use, you will need to obtain permission directly from the copyright holder. To view a copy of this licence, visit http://creativecommons.org/licenses/by/4.0/.

\section{References}

1. Scales CD, Smith AC, Hanley JM et al (2012) Prevalence of kidney stones in the United States. Eur Urol 62:160-165. https://doi. org/10.1016/j.eururo.2012.03.052

2. Croppi E, Ferraro PM, Taddei L et al (2012) Prevalence of renal stones in an Italian urban population: a general practicebased study. Urol Res 40:517-522. https://doi.org/10.1007/ s00240-012-0477-z

3. Lotan Y (2009) Economics and cost of care of stone disease. Adv Chronic Kidney Dis 16:5-10. https://doi.org/10.1053/j.ackd.2008. 10.002

4. Soucie JM, Thun MJ, Coates RJ et al (1994) Demographic and geographic variability of kidney stones in the United States. Kidney Int 46:893-899

5. Shavit L, Ferraro PM, Johri N et al (2015) Effect of being overweight on urinary metabolic risk factors for kidney stone formation. Nephrol Dial Transplant 30:607-613. https://doi.org/10. 1093/ndt/gfu350

6. Madore F, Stampfer MJ, Rimm EB, Curhan GC (1998) Nephrolithiasis and risk of hypertension. Am J Hypertens 11:46-53. https://doi.org/10.1016/s0895-7061(97)00371-3

7. Taylor EN, Stampfer MJ, Curhan GC (2005) Diabetes mellitus and the risk of nephrolithiasis. Kidney Int 68:1230-1235. https:// doi.org/10.1111/j.1523-1755.2005.00516.x

8. Spatola L, Ferraro PM, Gambaro G et al (2018) Metabolic syndrome and uric acid nephrolithiasis: insulin resistance in focus. Metab Clin Exp 83:225-233. https://doi.org/10.1016/j.metabol. 2018.02.008

9. Alexander RT, Hemmelgarn BR, Wiebe N et al (2014) Kidney Stones and Cardiovascular Events: A Cohort Study. CJASN 9:506-512. https://doi.org/10.2215/CJN.04960513

10. Fabris A, Ferraro PM, Comellato G et al (2015) The relationship between calcium kidney stones, arterial stiffness and bone density: unraveling the stone-bone-vessel liaison. J Nephrol 28:549-555. https://doi.org/10.1007/s40620-014-0146-0

11. Yiu AJ, Callaghan D, Sultana R, Bandyopadhyay BC (2015) Vascular calcification and stone disease: a new look towards the mechanism. J Cardiovasc Dev Dis 2:141-164. https://doi.org/10. 3390/jcdd2030141

12. Ferraro PM, Robertson WG, Johri N et al (2015) A London experience 1995-2012: demographic, dietary and biochemical characteristics of a large adult cohort of patients with renal stone disease. QJM 108:561-568. https://doi.org/10.1093/qjmed/hcu251

13. Patel ND, Ward RD, Calle J et al (2017) Vascular disease and kidney stones: abdominal aortic calcifications are associated with low urine $\mathrm{pH}$ and hypocitraturia. J Endourol 31:956-961. https:// doi.org/10.1089/end.2017.0350

14. Słojewski M (2011) Major and trace elements in lithogenesis. Cent Eur J Urol 64:58-61. https://doi.org/10.5173/ceju.2011.02.art1

15. Leenders NHJ, Vervloet MG (2019) Magnesium: a magic bullet for cardiovascular disease in chronic kidney disease? Nutrients 11:455. https://doi.org/10.3390/nu11020455

16. Ishimura E, Okuno S, Kitatani K et al (2007) Significant association between the presence of peripheral vascular calcification and lower serum magnesium in hemodialysis patients. Clin Nephrol 68:222-227. https://doi.org/10.5414/cnp68222

17. Sakaguchi Y, Hamano T, Obi Y et al (2019) A Randomized trial of magnesium oxide and oral carbon adsorbent for coronary artery calcification in predialysis CKD. J Am Soc Nephrol 30:10731085. https://doi.org/10.1681/ASN.2018111150

18. Paul AA, Southgate DA, Buss DH (1986) McCance and Widdowson's "The composition of foods": supplementary information and review of new compositional data. Hum Nutr Appl Nutr 40:287-299 
19. Levey AS, Stevens LA, Schmid CH et al (2009) A New Equation to Estimate Glomerular Filtration Rate. Ann Intern Med 150:604-612

20. Remer T, Dimitriou T, Manz F (2003) Dietary potential renal acid load and renal net acid excretion in healthy, free-living children and adolescents. Am J Clin Nutr 77:1255-1260. https://doi.org/ 10.1093/ajen/77.5.1255

21. Robertson WG (2003) A risk factor model of stone formation. Front Biosci 8:s1330-1338. https://doi.org/10.2741/1181

22. Ferraro PM, Taylor EN, Eisner BH et al (2013) History of kidney stones and the risk of coronary heart disease. JAMA 310:408-415. https://doi.org/10.1001/jama.2013.8780

23. Chen J, Budoff MJ, Reilly MP et al (2017) Coronary Artery Calcification and Risk of Cardiovascular Disease and Death Among Patients With Chronic Kidney Disease. JAMA Cardiol 2:635-643. https://doi.org/10.1001/jamacardio.2017.0363

24. Reiner Alexander P, Arnold K, Brian E H., et al (2011) Kidney stones and subclinical atherosclerosis in young adults: the CARDIA Study. J Urol 185:920-925. https://doi.org/10.1016/j.juro. 2010.10.086

25. Peng J-P, Zheng H (2017) Kidney stones may increase the risk of coronary heart disease and stroke: a PRISMA-Compliant metaanalysis. Medicine. https://doi.org/10.1097/MD.0000000000 007898

26. Ferraro PM, Marano R, Primiano A et al (2019) Stone composition and vascular calcifications in patients with nephrolithiasis. J Nephrol 32:589-594. https://doi.org/10.1007/ s40620-019-00619-w

27. Laakso M, Kuusisto J (2014) Insulin resistance and hyperglycaemia in cardiovascular disease development. Nat Rev Endocrinol 10:293-302. https://doi.org/10.1038/nrendo.2014.29

28. Cupisti A, Meola M, D’Alessandro C et al (2007) Insulin resistance and low urinary citrate excretion in calcium stone formers. Biomed Pharmacother 61:86-90. https://doi.org/10.1016/j.biopha. 2006.09.012
29. Gianella FG, Prado VE, Poindexter JR et al (2021) Spot urinary citrate-to-creatinine ratio is a marker for acid-base status in chronic kidney disease. Kidney Int 99:208-217. https://doi.org/ 10.1016/j.kint.2020.07.006

30. Goraya N, Simoni J, Sager LN et al (2019) Urine citrate excretion as a marker of acid retention in patients with chronic kidney disease without overt metabolic acidosis. Kidney Int 95:1190-1196. https://doi.org/10.1016/j.kint.2018.11.033

31. Houillier P (2014) Mechanisms and regulation of renal magnesium transport. Annu Rev Physiol 76:411-430. https://doi.org/10. 1146/annurev-physiol-021113-170336

32. Joosten M, Gansevoort R, Mukamal K et al (2012) Urinary magnesium excretion and risk of cardiovascular disease in the general population. Kidney Res Clin Pract 31:A40. https://doi.org/ 10.1016/j.krcp.2012.04.418

33. Yuan Q, Xie Y, Peng Z et al (2021) Urinary magnesium predicts risk of cardiovascular disease in Chronic Kidney Disease stage 1-4 patients. Clin Nutr 40:2394-2400. https://doi.org/10.1016/j. clnu.2020.10.036

34. Pascual E, Perdiguero M (2006) Gout, diuretics and the kidney. Ann Rheum Dis 65:981-982. https://doi.org/10.1136/ard.2005. 049023

35. Pak CY, Peterson R, Sakhaee K et al (1985) Correction of hypocitraturia and prevention of stone formation by combined thiazide and potassium citrate therapy in thiazide-unresponsive hypercalciuric nephrolithiasis. Am J Med 79:284-288. https://doi.org/10. 1016/0002-9343(85)90305-5

36. Ryan MP, Devane J, Ryan MF, Counihan TB (1984) Effects of diuretics on the renal handling of magnesium. Drugs 28(Suppl 1):167-181. https://doi.org/10.2165/00003495-198400281-00017

Publisher's Note Springer Nature remains neutral with regard to jurisdictional claims in published maps and institutional affiliations.

\section{Authors and Affiliations}

\section{Matteo Bargagli ${ }^{1}$ Shabbir Moochhala ${ }^{2}$. William G. Robertson ${ }^{2,3}$. Giovanni Gambaro ${ }^{4}$ - Gianmarco Lombardi ${ }^{4}$. Robert J. Unwin ${ }^{2} \cdot$ Pietro Manuel Ferraro ${ }^{1,5}$}

Pietro Manuel Ferraro

pietromanuel.ferraro@unicatt.it

1 U.O.S. Terapia Conservativa della Malattia Renale Cronica, U.O.C. Nefrologia, Fondazione Policlinico Universitario A. Gemelli IRCCS, Università Cattolica del Sacro Cuore, Largo Agostino Gemelli 8, 00168 Rome, Italy

2 Department of Renal Medicine, Royal Free Campus Medical School, University College Hospital, London, UK
3 Nuffield Department of Surgical Sciences, University of Oxford, Oxford, UK

4 Renal Unit, Division of Nephrology and Dialysis, Department of Medicine, University of Verona, Verona, Italy

5 Dipartimento Universitario di Medicina e Chirurgia Traslazionale, Università Cattolica del Sacro Cuore, Rome, Italy 